\title{
RESEÑA: LOS BRIGADISTAS DE HABLA INGLESA Y LA GUERRA CIVIL ESPAÑOLA. ANTONIO R. CELADA, MANUEL GONZÁLEZ DE LA ALEJA, DANIEL PAS- TOR GARCÍA ${ }^{1}$
}

\author{
Fernando Ballesteros Castillo ${ }^{2}$
}

\begin{abstract}
Celada, Antonio R., Manuel González de la Aleja, Daniel Pastor García. 2006. Los brigadistas de habla inglesa y la Guerra Civil Española. Salamanca: Almar. 501 páginas. ISBN: 84-7455-108-0.
\end{abstract}

Una publicación más se añade a las ya existentes sobre la Guerra Civil Española y las Brigadas Internacionales (BI). Si bien el tema, o mejor dicho los temas, del libro versan sobre diversos aspectos, todos ellos están relacionados con las Brigadas: breve historia de la guerra y las BI, las BI y los escritores de habla inglesa relacionados con ellas. Hasta aquí llega la mitad del libro, mientras que la otra mitad se dedica al recuerdo de los brigadistas en el cine (con un registro de las películas en donde aparecen referencias a estos voluntarios), en periódicos, libros o monumentos repartidos por varios países. Se completa la obra con dos apéndices: uno sobre las fuentes documentales que existen en la actualidad y que hacen referencia a las BI de habla inglesa. El otro, más extenso, consiste en un listado con los nombres de los internacionales cuya lengua materna era el inglés; este apartado consta de más de ciento cincuenta páginas y es, con mucho, la sección más amplia del libro.

La Guerra Civil Española, desde sus comienzos hasta nuestros días, ha suscitado un enorme interés. Se conocen alrededor de 35.000 publicaciones referentes a nuestro reciente y trágico pasado, aunque muchas de ellas carentes de objetividad. Deben pasar todavía muchos años para que cicatricen las heridas y desde la lejanía del tiempo se pueda escribir sobre este tema sin prejuicios, tal y como hoy hacemos con las guerras civiles que desangraron la Roma antigua: Mario contra Sila, César contra Pompeyo, Augusto contra Marco Antonio.

La guerra, que no el conflicto, comenzó el 18 de julio de 1936 cuando el pronunciamiento militar, similar a los que se producían en el siglo XIX, no triunfó en toda España debido a la división existente en el Ejército, que no era sino un reflejo de lo que sucedía en el resto de la sociedad española. La Segunda República sufrió tres embites. El primero fue un pronunciamiento clásico por parte del general Sanjurjo en 1932, que se llamó "la Sanjurjada". A diferencia de los pronunciamientos del siglo anterior el gobierno no cayó,

\footnotetext{
Fecha de recepción: octubre 2007.

Fecha de aceptación y versión definitiva: octubre 2007.

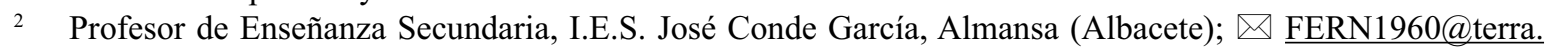
es.
} 
esencialmente porque este grupo de militares era muy reducido y carecía de apoyo civil. El segundo intento de derrocar al gobierno por la fuerza lo protagonizaron socialistas y comunistas en octubre de 1934; la excusa fue la entrada en el ejecutivo de tres ministros de la CEDA, que curiosamente había ganado las elecciones el año anterior (Payne 2005). Este asalto al poder por medio de las armas también fracasó por falta de apoyo popular aunque, a diferencia del de Sanjurjo, tuvo un componente sangriento en Asturias donde los sublevados controlaron una parte del territorio.

Y a la tercera va la vencida. Una sociedad dividida, con ganas de revancha encuentra la excusa perfecta. Una parte de la sociedad civil apoya el golpe, la otra no. Lo mismo ocurre en el ejército; unos se suman a la sublevación y otros no. En las zonas industrializadas de España (Madrid, Cataluña, Valencia, País Vasco y Cornisa Cantábrica) y en algunas zonas rurales como Murcia, Castilla La Mancha, parte de Andalucía y Extremadura, donde abundan los jornaleros y obreros, la sublevación fracasa. No así en Galicia, Aragón, Castilla León, norte de Extremadura, parte de Andalucía y los territorios extrapeninsulares, es decir, allá donde el reparto de la tierra propicia pequeños y medianos propietarios y apenas existe industria. O sea, donde no hay muchos obreros y jornaleros, que en aquella época estaban afiliados a organizaciones sindicales de carácter marxista o anarquista.

Estas dos Españas comienzan el enfrentamiento en solitario, pero muy temprano las dos recurren a la ayuda extranjera (Salas Larrazabal 1974). Son múltiples los estudios realizados sobre la cantidad de material y personal que recibió cada uno de los contendientes pero, como comenté anteriormente, la mayoría son claramente partidistas. Sea como fuere en septiembre de 1936 se reúnen en Moscú los secretarios generales de los partidos comunistas de Francia, Italia, España y la Unión Soviética (Delperrie de Bayac 1982). Bajo la atenta mirada de Stalin deciden formar unas unidades militares financiadas y controladas por la Internacional Comunista a través de sus diferentes ramificaciones: sindicatos, Socorro Rojo Internacional, Frente Rojo... No olvidemos que la idea de los Frentes Populares partió de Stalin, quien ordenó a los dirigentes comunistas de Francia y España que formasen estas coaliciones con otros partidos de izquierda.

De esta forma el 14 de octubre de 1936, apenas tres meses después de comenzar la guerra, llegan a Albacete los primeros 500 voluntarios internacionales. Y hasta que Negrín comunica en la Sociedad de naciones el 21 de septiembre de 1938, en plena crisis de Munich (Alonso Baquer 2003), la retirada de los extranjeros que combaten en las filas del Ejército Popular de la República, aproximadamente 31.000 internacionales de diferentes países militarán en las BI (Radosh 2002). De todos ellos unos 7000 eran angloparlantes, aunque la lengua oficial de las BI fue el francés y más tarde también el alemán, ya que alrededor del cincuenta por ciento de los voluntarios hablaban la lengua de nuestros vecinos del norte (Castells 1974).

Las BI participaron en casi todos los escenarios bélicos importantes de la guerra con mayor o menor fortuna. Su bautismo de fuego sería en noviembre de 1936 en la Casa de Campo y la Ciudad Universitaria, en marzo vendría el Jarama y Guadalajara. Y durante la primavera y el verano las sangrientas luchas en Brunete y Belchite, el terrible invierno en Teruel y finalmente la decisiva y gran batalla del Ebro en el verano de 1938. Por fortuna para muchos de ellos la orden de retirada se produjo antes de la última ofensiva nacional lo que les supuso salvarse de una más que probable aniquilación. 
Fueron evacuados unos 10.000 según la Comisión Internacional para la Retirada de Extranjeros (Martínez Bande 1972). Sin embargo, no todos los países de origen de los brigadistas quisieron admitirlos y no tuvieron más remedio que continuar en España. El 30 de abril de 1939, un día antes de finalizar la guerra, vamos a encontrarnos algunos en el puerto de Alicante intentando embarcar en un buque británico (Ballesteros 2006).

Como corresponde al enfoque que sigue el libro que nos ocupa, los autores hacen una descripción de los distintos batallones anglófonos: el batallón británico, el batallón canadiense "Mac-Pap" y el más famoso de todos, el estadounidense "Abraham Lincoln".

En el capítulo dedicado a los brigadistas y voluntarios de habla inglesa y la literatura, los autores analizan las obras literarias más importantes relacionadas con las BI. Mención obligatoria en este comentario merece el libro de Hemingway Por quién doblan las campanas, también llevada al cine. Aunque los tres escritores de mayor relieve fueron, junto al mencionado arriba, George Orwell y Arthur Koestler, ninguno de ellos perteneció a las brigadas, aunque estuvieron en nuestra guerra y escribieron sobre ella. En el caso de Orwell no conviene pasar por alto su extraordinaria obra Homenaje a Cataluña, donde relata sus peripecias en una unidad militar del POUM (partido de orientación comunista pero antiestalinista). Especialmente interesantes son los dramáticos momentos de la purga stalinista entre las filas del POUM, en las que el propio Orwell se salvaría por los pelos. Curiosamente en estos asesinatos de militantes poumistas se verían implicados algunos brigadistas de origen alemán en el secuestro y tortura del líder Andreu Nin (Zavala 2005).

Otro de los capítulos importantes del libro es la bibliografía comentada, donde los autores analizan las publicaciones realizadas hasta la fecha sobre los brigadistas de habla inglesa. También es de agradecer la descripción de las fuentes documentales y el lugar donde se encuentran, por si algún futuro investigador se decidiera a profundizar más sobre este tema. En cuanto a la bibliografía que han consultado, es abundante y actualizada aunque, en mi opinión, les falta la mejor de todas: Historia del Ejército Popular de la República, de varios tomos y sin lugar a dudas la mejor obra que se haya publicado al respecto, escrita por uno de nuestros mejores historiadores militares Ramón Salas Larrazabal.

Como conclusión cabe añadir que el presente libro, aunque con alguna carencia, constituye una aportación valiosa al estudio de las Brigadas Internacionales, pero sobre todo puede ser un trabajo muy fiable y serio para los estudiosos de literatura inglesa.

\section{REFERENCIAS BIBLIOGRÁFICAS}

Alonso Baque, M. A. 2003. El Ebro. La batalla decisiva de los cien días. Madrid: La Esfera de los Libros.

Ballesteros Castillo, F. 2006. Las Brigadas Internacionales. Madrid: Editorial San Martín.

CAstell, A. 1974. Las Brigadas Internacionales de la guerra de España. Barcelona: Ariel.

DelPerrie de BayaC, J. 1980. Las Brigadas Internacionales. Madrid: Júcar.

Martínez Bande, J. M. 1972. Las Brigadas Internacionales. Barcelona: Luis de Caralt. 
Payne, S.G. 2005. El Colapso de la República. Madrid: La Esfera de los Libros.

Radosh, R., M. R. Habeck y G.N. Sevostianov, eds. 2002. España traicionada. Stalin y la Guerra Civil. Barcelona: Planeta.

Salas LarRazabal, J. 1974. Intervención extranjera en la guerra de España. Madrid: Editora Nacional.

Salas Larrazabal, R. 2006. Historia del ejército popular de la República. Madrid: La Esfera de los Libros.

Zavala, J. M. 2005. En busca de Andreu Nin. Barcelona: Plaza y Janés. 